Revista lus et Praxis, Año 23, № 2, 2017, pp. 485 - 506

ISSN 0717 - 2877

Universidad de Talca - Facultad de Ciencias Jurídicas y Sociales

La potestad normativa sancionadora municipal.

Análisis de la operatividad del principio de legalidad

Rosa Fernanda Gómez González

Trabajo recibido el 29 de noviembre de 2015 y aprobado el 3 de mayo de 2016

\title{
La potestad normativa sancionadora municipal. Análisis de la operatividad del principio de legalidad
}

THE MUNICIPAL AUTHORITY REGULATIONS SANCTIONING.

ANALYSIS OF THE OPERATION OF THE PRINCIPLE OF LEGALITY

Rosa Fernanda Gómez Gonzálezz

RESUMEN

La presente investigación tiene por objeto establecer la existencia de una potestad normativa sancionadora municipal a través de la emisión de ordenanzas locales, identificando las bases constitucionales y legales de la misma, para, a continuación, precisar el rol que juega el principio de legalidad en este ámbito. Asimismo, se precisarán cuáles son los límites que debe observar el ejercicio de la dicha potestad.

ABSTRACT

This research aims to establish the existence of a regulatory authority sanctioning city through the issuance of local, identifying the constitutional and legal bases of it, to then pinpoint the role played by the rule of law in this scope. They will be needed which are the limits to be observed by the exercise of that power.

Palabras Clave

Municipalidades, Sanciones, Ordenanzas

KEY WORDS

Municipalities, Penalties, Ordinances

\section{La potestad sancionadora de la Administración}

\section{Consideraciones previas}

Antaño en nuestro país los esfuerzos doctrinales y jurisprudenciales estuvieron abocados a justificar y fundamentar la potestad punitiva de los órganos de la Administración del Estado. Al efecto, las posiciones oscilaban entre una negativa rotunda en tal sentido por motivos de inconstitucionalidad ${ }^{1}$, hasta

\footnotetext{
* Abogada, Magíster en Derecho Regulatorio. Candidata a Doctora en Derecho por Pontificia Universidad Católica de Valparaíso. Beneficiaria Beca Conicyt-PCHA/Doctorado Nacional/2016-Folio No 21160419. Asimismo este trabajo es parte de una investigación financiada por Fondecyt bajo el título: "Análisis y revisión dogmática del Derecho Administrativo Sancionador en Chile a partir de su parte Especial" № 1161741. Correo electrónico: HYPERLINK “Mailto: rsgomez@uc.cl”; rsgomez@uc.cl.

${ }^{1}$ Sото (2014), р. 39.
} 
su aceptación casi por razones históricas, vinculadas con la satisfacción oportuna y eficaz de necesidades públicas y la protección del bien común, eso sí, bajo la inquebrantable regla de revisión judicial posterior ${ }^{2}$.

Dejada atrás esa discusión y asumiendo la constitucionalidad de esta potestad, el problema que se suscitó fue la determinación del estatuto jurídico aplicable a esta incipiente disciplina. Para tal efecto la doctrina y la jurisprudencia han debido atender una importante interrogante, a saber, cuál o cuáles serían los principios que informarían la actividad sancionadora de la Administración del Estado en Chile, dada la inexistencia de un régimen jurídico predefinido ${ }^{3}$.

Sobre este aspecto, García de Enterría -ya en el año 1976, esto es, antes de la existencia del art. 25 incorporado por la Constitución de $1978^{4}$ - señalaba que la inexistencia de un cuadro normativo común aplicable a las sanciones administrativas no podía interpretarse como una habilitación a la Administración para la aplicación arbitraria y grosera de sus facultades represivas, sino que se trata de una laguna que habría de integrarse necesariamente con técnicas propias del Derecho Penal ordinario 5 . El mismo autor sostuvo posteriormente que "la jurisprudencia -ya amparada en el artículo 25 de su Carta Fundamental-solucionó el problema de la inexistencia de un cuerpo normativo general que regulara los principios que han de inspirar el sistema sancionador administrativo" ${ }^{6}$.

En igual sentido, Franck Moderne indicaba que la sanción administrativa ocupa un lugar significativo en los sistemas jurídicos occidentales y que en

\footnotetext{
${ }^{2}$ Al respecto véanse Aróstica (1987), p. 81, y (1991), pp. 173 y ss.; Bermúdez (2014), p. 328; Cordero y Aldunate (2012), pp. 337-361. Disponible en: http://www.scielo.cl/scielo.php?script=sci_ arttext\&pid=S0718-68512012000200013\&lng=es\&nrm=iso (también en CORDERO (2014), pp. 121-160), entre otros.

${ }^{3}$ Cabe recordar que mediante el Boletín № 3475-06 se presentó por parte del Presidente de la República, ante el Senado, un proyecto de ley que establecía las bases de los procedimientos administrativos sancionatorios. En dicho texto se efectuó un reconocimiento expreso de la potestad administrativa sancionadora, haciendo presente el apremio por instaurar una regulación legal tendiente a controlar el poder de la administración, para así evitar que este sea inconsulto, arbitrario e ilimitado. Este proyecto fue archivado en agosto de 2006 cuando se encontraba en primer trámite constitucional.

${ }^{4}$ La Constitución española de 1978 incorporó en su art. 25 el siguiente texto: "1. Nadie puede ser condenado o sancionado por acciones u omisiones que en el momento de producirse no constituyan delito, falta o infracción administrativa, según la legislación vigente en aquel momento".

${ }^{5}$ García de Enterría (1976), pp. 399 y ss.

${ }^{6}$ García de Enterría y Fernández (2011), pp. 174-175. En efecto, la ausencia de un cuadro normativo que definiese los principios generales de funcionamiento de las sanciones administrativas fue suplida por la remisión general a "los principios del orden penal".

En cuanto a la delimitación que existiría entre el Derecho Penal y el Derecho Administrativo véase el interesante análisis ofrecido en Cerezo (2008), pp. 40-53.
} 
todos ellos se aprecia la voluntad del juez constitucional y del legislador, en su caso, de establecer para el ejercicio de esta potestad reglas claras de fondo y de procedimiento inspiradas en los principios garantizados de un Derecho Penal secularmente decantado ${ }^{7}$.

A nivel nacional, sin perjuicio de la abundante doctrina que ya existe sobre la materia, ha sido en gran medida la jurisprudencia la que se ha encargado de precisar las directrices del Derecho Administrativo Sancionador. Es así como en el campo de los principios el Tribunal Constitucional ha sostenido que el ejercicio sancionador por parte de la Administración se debe someter por regla genera $^{8}$ o con matices ${ }^{9}$ a los límites de los principios inspiradores del orden penal contemplados en la Constitución. Dicho Tribunal ha señalado que aun cuando las sanciones administrativas y las penas difieren en algunos aspectos, ambas pertenecen a una misma actividad sancionadora del Estado, esto es, el Ilamado ius puniendi y están sujetas al estatuto constitucional del art. 19, $\mathrm{N}^{\circ} 3^{10}$. Como se puede apreciar, por una parte, el Tribunal no se cuestiona la constitucionalidad de las sanciones administrativas, sino que busca establecer cuál es el régimen jurídico constitucional aplicable y, por la otra, parece sostener que los principios constitucionales que disciplinan el poder punitivo estatal son aplicables de forma estricta en el ámbito penal, pero no con la misma

\footnotetext{
${ }^{7} \mathrm{Al}$ respecto véase MOderne (1993), pp. 5 y ss.

${ }^{8}$ STC rol No 244, la que sostuvo en su considerando 90: "Que, los principios inspiradores del orden penal contemplados en la Constitución Política de la República han de aplicarse, por regla general, al derecho administrativo sancionador, puesto que ambos son manifestaciones del ius puniendi propio del Estado" (la cursiva es nuestra).

${ }^{9}$ STCs roles $\mathrm{N}^{\circ} \mathrm{s} .479$ (considerando $8^{\circ}$ ) y 480 (considerando $5^{\circ}$ ). En concreto, tales sentencias señalaron que el principio de legalidad es igualmente aplicable a la actividad sancionadora de la administración en virtud de lo prescrito en los dos últimos incisos del numeral 3 del art.19 de la Carta Fundamental. Aun cuando las sanciones administrativas y las penas difieren en algunos aspectos, ambas pertenecen a una misma actividad sancionadora del Estado -el Ilamado ius puniendi-y están, con matices, sujetas al estatuto constitucional establecido en el numeral $3^{\circ}$ del art. 19 .

Al respecto cabe manifestar que Román Cordero expresa acerca del cambio de la terminología "por regla general" a la fórmula "con matices", que "(...) constituye, a mi juicio, un importante cambio jurisprudencial, pues la voz 'con matices', que emplean estas sentencias, es más restrictiva que la utilizada por la $N^{\circ} 244$-'por regla general'-, ya que, a diferencia de esta última, no autorizarían desviaciones o excepciones al modelo penal, con lo cual, erróneamente, a mi juicio, el Tribunal Constitucional ha acercado el Derecho Administrativo Sancionador al Derecho Penal, poniendo con ello en entredicho su autonomía -que le es consustancial, conforme he explicado-, y ha enfatizado, a su vez, su rol garantista, en desmedro de aquél que lo singulariza: la protección del interés público", en Román (2009), p. 96.

${ }^{10}$ A modo ilustrativo podemos citar las STCs roles $\mathrm{N}^{\circ}$ s. 244, 479, 480, 725, 747, 766, 1183 y 1518.
} 
rigurosidad a las sanciones que impone la Administración, sin que se explique el porqué de estas matizaciones ni el diverso tratamiento ${ }^{11}$.

Alguna doctrina da razones de este tratamiento diferenciado argumentando que las sanciones administrativas son de menor gravedad que las sanciones penales - por lo menos no pueden acarrear la privación de libertad ${ }^{12}-$ y que la necesidad de una oportuna intervención administrativa exige garantías formales y materiales más flexibles que las del sector penal ${ }^{13}$, de tal forma, se resguardaría un núcleo básico de garantías para el ius puniendi administrativo, pero se flexibilizarían otros en aras de una mayor eficacia ${ }^{14}$. Con todo,

${ }^{11}$ Cordero (2014), pp. 224-225.

${ }^{12}$ La historia demuestra que la existencia de sanciones administrativas consistentes en arrestos o privación de libertad se contemplaron de manera directa o con carácter subsidiario por el no pago de multas ( $v$. gr. la prevista en el derogado art. 169 del Código Sanitario).

Además, resta decir que las sanciones administrativas no son siempre de poca envergadura o de "bagatela" -como denomina la doctrina europea que postulaba la despenalización-, dado que actualmente la Administración ostenta importantes medidas represivas, tanto de supresión, restricción de derechos o de carácter pecuniario.

En este sentido, para Novoa las infracciones y los delitos parecen diferenciarse por su menor gravedad, por no contravenir un mínimo ético y por constituir, más que atentados contra un determinado bien jurídico, una especie de falta de colaboración del infractor hacia la autoridad en los esfuerzos de esta por promover el progreso y bienestar social. Luego, agregó que la proliferación de leyes penales administrativas y la mayor gravedad (ya en 1985) que van asumiendo hace aconsejable que el legislador se preocupe de rodear la aplicación del Derecho Penal Administrativo de garantías semejantes a las que están incorporadas al Derecho Penal, para mantener el respeto por la dignidad y los derechos del hombre. En NovoA (1985), pp. 27 y 32.

Para Enrique Bacigalupo es claro que el Derecho Penal Criminal y el Sancionatorio Administrativo forman parte del sistema jurídico de sanciones estatales y que toda política criminal debe diseñar un programa en el que se establezca con precisión qué conductas se pretende sancionar criminalmente y cuáles, por el contrario, se considerarán de un rango menor y solo merecedoras de sanciones administrativas. Véase BACIGALUPO (2004), p. 52.

${ }^{13}$ Sobre esta afirmación, Blanca Lozano Cutanda expresa que "(...) podemos sostener que el proceso despenalizador y el reconocimiento de la potestad sancionadora de la Administración responden a razones de política criminal que se basan, fundamentalmente, en la mayor eficacia de la actuación administrativa para la represión de determinados ilícitos"; prosigue señalando que "(...) la potestad sancionadora de la Administración surge por razones de tipo funcional, como colaboradora de la potestad punitiva jurisdiccional para la represión de ilícitos de gravedad menor (...)" (las cursivas son nuestras), en LozANo (1997), pp. 52 y ss.

${ }^{14}$ En tal sentido, el Tribunal Constitucional en su sentencia rol $N^{\circ} 479$, a propósito de un requerimiento de inaplicabilidad interpuesto por diversas compañías eléctricas en contra del artículo 15 de la ley $N^{\circ} 18.410$, precisa que el principio de legalidad rige la actividad sancionadora del Estado, pero su vigencia no impide que la administración pueda legítimamente sancionar conductas cuyo núcleo esencial se encuentre descrito en una ley y más extensamente desarrollado en normas reglamentarias. Esta colaboración es también admisible en el Derecho Penal, pero está regulada con mayor rigurosidad. Al efecto, Luis Rodríguez Collao señala que "[d]esde el punto de vista del principio de legalidad, lo ideal sería que todas las leyes penales fueran completas. Luego, todas las normas que dejan algún blanco que precise ser completado se alejan de aquel ideal, poniendo en peligro la garantía, algunas, 
una aplicación matizada de los referidos principios no se debiera distanciar demasiado de los estándares penales, por cuanto muchas infracciones administrativas imponen sanciones graves, privativas de derechos o pecuniarias de elevada cuantía ${ }^{15}$.

En suma, de lo expuesto se puede apreciar que el problema central de las sanciones administrativas ya no está en su fundamento constitucional, sino en las modulaciones de las garantías penales que puede establecer el ordenamiento jurídico para racionalizar su ejercicio ${ }^{16}$. En tal sentido, se debe hacer un análisis que permita ponderar los efectos y alcances de los principios y garantías del orden penal al Derecho Administrativo Sancionador, para adaptarlos a las particularidades de sus ilícitos, evitando traspasarlos mecánicamente ${ }^{17}$. En definitiva, la aplicación de los principios penales del orden constitucional a las sanciones administrativas no es ni íntegra ni mimética, sino que admite una diversidad de graduaciones, frente a lo cual los tribunales y los órganos administrativos jugarán un rol protagónico en la determinación de su operatividad real ${ }^{18}$.

\section{Prevención: lo que no es parte del núcleo del Derecho Administrativo Sancionador}

Brevemente, quiero precisar que existen ciertos tipos de represiones que usualmente suelen ser asociadas a la potestad sancionadora de la Administración, sin que estas la constituyan. Por ello, efectuaré una sucinta referencia a ellas, señalando qué es lo que las hace diferentes del Derecho Administrativo Sancionador propiamente tal.

Al efecto, cabe tener presente que la potestad sancionadora de la Administración está orientada a reprimir una conducta u omisión contraria a

o vulnerándola, otras. Todas ellas, sin embargo, por ser incompletas, deben ponernos en guardia frente a un posible atentado contra dicho principio.". Rodrícuez (1984), p. 244. En igual sentido, Sergio Yáñez Pérez expresa que "la aceptación de leyes penales en blanco, a pesar de los reparos parciales que se les hagan, es el hecho, muy claro para los penalistas, que la exigencia de determinación del tipo penal, se ve afectado en otros casos, por la naturaleza de la materia reglada". Indica que el artículo $19 \mathrm{~N}^{\circ} 3$ de la Constitución no contiene una prohibición expresa de las leyes penales en blanco, precisa que al exigir que la conducta que se sanciona esté expresamente descrita en la ley, requiere un grado de determinación necesaria del tipo penal para que sea efectiva la garantía de ley penal previa. Así, mientras el precepto describa esencialmente la conducta prohibida y entregue a la instancia reglamentaria aspectos secundarios de complementación, se satisfarían las exigencias del principio de legalidad. En Yáñez (1985), pp. 5 y ss.

${ }^{15}$ LozANO (1997), p. 57.

${ }^{16}$ En Aróstica (1991), pp. 189 y ss.; Camacho (2010), p. 184; y Cordero (2014), p. 130.

${ }^{17}$ Самасно (2010), p. 184.

${ }^{18}$ Véase Delus (1998), pp. 17-20. 
derecho de un particular. En este contexto, es la propia Administración la que, mediante la sujeción a un procedimiento sancionador previamente dispuesto en la ley, sujeto a una serie de principios, aplica las sanciones respectivas.

Esta potestad se distingue del denominado Derecho Administrativo Disciplinario, en virtud del cual, el órgano de que se trate reprime las actuaciones u omisiones de los funcionarios o servidores públicos que se encuentran bajo una relación de sujeción especial. Este vínculo que une a un funcionario con la Administración se caracteriza por la incorporación efectiva y duradera del servidor en la esfera organizativa de la Administración, quedando sometido de forma especialmente intensa, como consecuencia de esa incorporación a sus poderes de ordenación y control ${ }^{19}$. En otras palabras, la facultad disciplinaria atiende al orden interno del órgano de que se trate y el desempeño de sus funcionarios, consiste en los medios que tiene la Administración del Estado para reprimir las infracciones a la normativa administrativa, las que generalmente son ejercidas por el superior jerárquico para corregir al inferior ${ }^{20}$.

Enseguida, toca diferenciar una serie de actos que afectan la esfera jurídica de los particulares sin que ellos sean necesariamente expresión del ius puniendi estatal. Se trata de los actos administrativos de contenido desfavorable ${ }^{21}$, los cuales podemos distinguir entre:

i. Actos que no sean consecuencia de una conducta ilícita, como sería la expropiación, la suspensión de un concurso público o la extinción de un acto administrativo.

ii. Actos consecuencia de una conducta ilícita, pero que no tienen una finalidad represiva o reaccional. Las que podemos diferenciar en: a) Medidas de reestablecimiento: suspensión de una construcción de una obra que no tenía permiso de edificación o el cierre de un local comercial que no tenía permiso municipal y b) Medidas de reparación: reparación del perjuicio causa al patrimonio público.

Por último, debemos distinguir el Derecho Administrativo Sancionador del Derecho Correccional, los cuales consisten en aquellas sanciones impuestas por entidades privadas a las personas que integran un determinado grupo social, ej: bomberos, clubes sociales, asociaciones gremiales, colegio de abogados, médicos, entre otros.

\section{II. ¿Existe una potestad normativa sancionadora municipal?}

\section{Bases de una potestad normativa sancionatoria municipal}

\footnotetext{
${ }^{19}$ LOZANO (1997), p. 65.

${ }^{20}$ GarRido (1997), p. 84.

${ }^{21}$ Sobre los actos con efectos desfavorables y las sanciones administrativas véase CORDERO (2014), p. 34.
} 
El carácter expansivo que en Chile ha tenido el poder represivo de la administración es una realidad irrefutable. Así, algunos autores destacan este crecimiento exponencial y la lesividad de las sanciones, como una suerte de elefantiasis de las potestades sancionadoras de la Administración ${ }^{22}$.

$\mathrm{Al}$ abordar el estudio de la potestad normativa sancionadora municipal, podemos constatar que dicha potestad es tan antigua como los mismos municipios ${ }^{23}$, pues resultaría inimaginable su funcionamiento sin contar con tan importante e imprescindible medio para asegurar la eficacia de sus normas ${ }^{24}$. Pensemos que conductas habitualmente prohibidas en los municipios, tales como arrojar residuos sobre las calzadas públicas o colocar publicidad en cualquier sitio de los bienes nacionales de uso público, no llevasen aparejada la posibilidad de imponer a los autores una sanción. Entonces podríamos afirmar que el poder local consistente en organizar la convivencia dentro de sus límites territoriales perdería su potencialidad de ser cumplido por los destinatarios, quienes, a pesar de las interdicciones existentes, podrían soslayarlas sin que ello les reportase ninguna consecuencia ${ }^{25}$.

En Chile, la potestad normativa municipal está regulada en diversas disposiciones de la Ley № 18.695, Orgánica Constitucional de Municipalidades (LOCM), por ejemplo, en los arts. 50, letra d), 12, 63, letra i), y 65, letra k) ${ }^{26}$.

Con todo, estimo que el origen del poder punitivo local está radicado en el inc. $2^{\circ}$ del art. 12 de la LOCM, que previene: "Las ordenanzas serán normas generales y obligatorias aplicables a la comunidad. En ellas podrán establecerse multas para los infractores, cuyo monto no excederá de cinco unidades tributarias mensuales, las que serán aplicadas por los juzgados de policía local correspondientes $^{\prime 27}$. Salvo que se tratare de infracciones al decreto ley $\mathrm{N}^{0} 3.063$,

\footnotetext{
22 Román (2010), p. 157.

${ }^{23} \mathrm{Al}$ efecto, Luis Cordero señala que "existe bastante consenso en la doctrina especializada en que los municipios corresponden a organizaciones anteriores incluso al Estado nacional, considerándose por muchos una institución natural,". En CORDERO (2015), p. 211.

${ }^{24}$ Nieto (2012), p. 85.

${ }^{25}$ Ortuño (2009), p. 24.

${ }^{26} \mathrm{Al}$ efecto véase la STC rol No 1669 , considerandos 17 y ss.

Por su parte, no se puede olvidar que el art. 501 del Código Penal establece que "[e]n las ordenanzas municipales y en los reglamentos generales o particulares que dictare en lo sucesivo la autoridad administrativa no se establecerán mayores penas que las señaladas en este libro, aun cuando hayan de imponerse en virtud de atribuciones gubernativas, a no ser que se determine otra cosa por leyes especiales".

${ }^{27}$ La primera regulación que definió las ordenanzas municipales fue el decreto ley $N^{0} 740$, de 1925 , señalando que "se entiende por ordenanza únicamente las reglas de general aplicación" (artículo $49 \mathrm{~N}^{\circ}$ 2). Esta definición reaparece en el art. 13 del decreto ley $\mathrm{N}^{\circ} 1.289$, de 1975 ("las ordenanzas
} 
de 1979, en cuyo caso los municipios no podrán establecer multas que excedan de 3 UTM, según lo prescrito en el art. 56 de este último texto legal ${ }^{28}$.

En dicho precepto se advierte un reconocimiento tácito y genérico del ius puniendi municipal, sin una referencia concreta a la tipificación de las posibles infracciones. En concreto, los municipios pueden establecer sanciones en sus ordenanzas por contravenciones a las disposiciones contenidas en las mismas (facultad normativa), quedando el conocimiento y aplicación de la sanción respectiva a cargo de los jueces de Policía Local.

Como se puede advertir, este reconocimiento tiene un carácter restringido, el que está dado por un límite respecto del tipo de sanción, su cuantía y el territorio en que se cometa la falta. De tal modo, solo se podrá imponer una sanción pecuniaria de hasta 5 UTM por las contravenciones que acontezcan dentro de la "comunidad" local (límite espacial), las que serán aplicadas por los juzgados de Policía Local respectivos conforme al procedimiento ordinario dispuesto para esa instancia.

En tal contexto, cabe analizar si podemos considerar las ordenanzas como el instrumento adecuado para la tipificación de infracciones y para la determinación de las correspondientes sanciones, dados los límites establecidos.

\section{Las ordenanzas municipales como fuente del Derecho sancionador municipal}

No cabe duda de que las ordenanzas juegan un rol protagónico en el desarrollo de la potestad normativa sancionadora municipal, en la medida en que sus disposiciones se ajusten a los principios que informan el ejercicio del ius puniendi estatal.

Se trata de preceptos jurídicos establecidos por las corporaciones de derecho público en el marco de la autonomía que les es conferida por la ley (Constitución) $^{29}$. Por lo tanto, para su emisión, el órgano local requiere de una autorización legal que defina su contenido y extensión, autorización que en Chile está dada en el art. 12 LOCM, como hemos visto ${ }^{30}$.

En concreto, se trata de instrumentos jurídicos unilaterales que crean normas jurídicas, pues incorporan disposiciones al ordenamiento jurídico, innovándolo. Contienen normas de carácter general, es decir, van dirigidas a situaciones o

serán normas generales y obligatorias aplicables a la comunidad"') y luego de su derogación, en el citado art. 12 .

${ }^{28}$ Para estos efectos véase el dictamen No 42.450, de 2013.

${ }^{29}$ Forsthoff (1958), p. 204.

${ }^{30}$ Tratándose de la ordenanza de participación ciudadana, la autorización está en el art. 93 LOCM, y de la ordenanza ambiental en el art. 25 letra f) LOCM. 
sujetos indeterminados, y obligatorias para la comunidad, esto es, gozan de imperio desde su publicación ${ }^{31}$.

Son dictadas a través de un procedimiento que importa el ejercicio de una facultad compartida entre el alcalde y el concejo municipal, en donde el primero tiene la iniciativa en la materia y al concejo le corresponde su aprobación (art. 65, letra k), art. 79, letra b), de la LOCM). El quórum de aprobación es de la mayoría absoluta de los concejales asistentes a la sesión respectiva (art. 86 LOCM). Se trata, por tanto, de un acto administrativo municipal dotado de un alto grado de legitimidad.

Dada su eficacia normativa externa, requieren ser publicadas. La comunidad tiene derecho a que se le comunique el contenido del acto municipal en forma oportuna y adecuada. Sobre este punto, cabe señalar que para efectos de transparencia y conforme a lo señalado en el inciso final del art. 12 de la LOCM, es preciso que las ordenanzas estén a disposición del público para lo cual es imperativa su incorporación en los sistemas electrónicos o digitales de que disponga la municipalidad ${ }^{32}$. Por su parte, tratándose de la publicidad, para que surtan efecto sus disposiciones y, por tanto, que adquieran el carácter de obligatorias para la comunidad, es necesario que este acto sea publicado en el Diario Oficial ${ }^{33}$, según lo dispone el artículo 48 de la ley $N^{\circ} 19.880$, a menos que exista normativa especial que establezca una forma de publicidad diversa ${ }^{34}$.

\footnotetext{
${ }^{31}$ Véase también el concepto señalado en BERMúdeZ (2014), p. 748.

${ }^{32}$ Cabe tener presente que el inciso final del art. 12 fue incorporado por el artículo $4^{\circ} \mathrm{N}^{\circ} 1$ de la ley № 20.285, ley que regula, en lo que interesa, el principio de transparencia de la función pública, el derecho de acceso a la información de los órganos de la Administración del Estado.

Es por ello que no estamos de acuerdo con la interpretación sostenida por la Contraloría General de la República en de su dictamen № 26.019, de 2010, en el que señala que a partir de la vigencia del actual inciso final del citado artículo 12 -20 de abril de 2009-, la ordenanza por la que se consulta (sobre Aseo, Ornato y Protección del Medio Ambiente y Salud Ambiental) ha podido ser válidamente difundida en la página web de ese municipio, no siendo actualmente necesaria su publicación en el Diario Oficial, ello por cuanto confunde la obligación de transparencia con la de publicidad de los actos administrativos (este criterio fue sostenido posteriormente en los dictámenes $\mathrm{N}^{\circ} \mathrm{s} .60 .748$ y 64.338, ambos de 2011).

${ }_{33}$ Dictámenes Nos. 26.378, de 2008, y 7.092, de 2009.

Sobre la publicación en el Diario Oficial, cabe tener presente que conforme a lo dispuesto en el artículo 17 del decreto № 22, de 2016, del Ministerio del Interior y Seguridad Pública, que Aprueba el reglamento sobre organización y funcionamiento del Diario Oficial de la República de Chile, los requerimientos de publicación en dicho diario, efectuados a petición de los órganos del Estado, no tienen aparejada una tarifa, por lo cual, los municipios no incurrirían en desembolsos para tales efectos.

${ }^{34} \mathrm{Al}$ efecto, Contraloría ha señalado que en virtud del principio de especialidad es posible inferir que solo respecto de las ordenanzas de que trata el artículo 42 de la Ley de Rentas Municipales, rigen las reglas de publicación a que alude su inciso tercero (Diario Oficial o en la página web de la municipalidad respectiva o en un diario regional de entre los tres de mayor circulación de la respectiva comuna),
} 
Enseguida, cabe anotar que la LOCM distingue dos tipos de ordenanzas, a saber: las generales, que abordan las materias propias del municipio, que no estén contempladas en las ordenanzas singulares, y las especiales, respecto de las cuales la ley define su contenido de modo particular, como las ambientales (art. 25, letra f)) y la de participación de la ciudadanía local (art. 93).

Asimismo, es preciso destacar que el contenido de estos instrumentos puede ser objeto de un reclamo de ilegalidad municipal (art. 151 LOCM) o de una revisión de su legalidad ante la Contraloría General de la República ${ }^{35}$.

En suma, las municipalidades pueden materializar el ejercicio de su ius puniendi mediante la emisión de una ordenanza de tipo general, respecto de los asuntos que conforme a la Constitución y a su ley orgánica les atañe administrar en el orden local, esto es materias "propias o nucleares"36, por ejemplo, la disposición de muebles en bienes nacionales de uso público -mesas, sillas, toldos, plantas, etc.-, la limpieza de canales de regadío, la recolección de basura, el aseo y ornato, el turismo, el deporte y recreación, entre otras tantas materias.

\section{Matizaciones al principio de legalidad en materia sancionadora municipal}

El Tribunal Constitucional, en uno de sus primeros fallos sobre la potestad sancionadora (STC rol No 244, de 1996), señaló, tal como lo enuncié previamente, que los principios inspiradores del orden penal contemplados en la Constitución han de aplicarse, por regla general, al derecho administrativo sancionador, puesto que ambos son manifestaciones del ius puniendi propio del Estado. Dicho fallo precisó que el principio de legalidad se cumple con la previsión legal de las infracciones y sanciones. Por lo que corresponde a la ley y solo a ella establecer al menos el núcleo esencial de las conductas que se sancionan, materia que es así, de exclusiva y excluyente reserva legal, en términos tales, que no procede a su respecto ni siquiera la delegación de facultades legislativas al Presidente de la República.

por cuanto en aquellos casos en que el ordenamiento jurídico ha contemplado una forma específica de publicación, esta debe materializarse del modo que prescribe la ley respectiva (dictámenes $\mathrm{N}^{\circ}$ s. 77, de 2005, y 26.378, de 2008).

${ }^{35} \mathrm{Al}$ efecto, en el dictamen № 54.713, de 2009, la Contraloría señaló que "(...) la circunstancia que los actos administrativos que dicten las municipalidades, por regla general, no se encuentren afectos al trámite de toma de razón, no es impedimento para el ejercicio de las restantes facultades que le competen a este Organismo de Control con el objeto de asegurar, en lo que interesa a la materia, la legalidad de los actos de esas corporaciones edilicias".

${ }^{36}$ Nieto (2012), p. 298. 
Diez años después, en la STC rol Nº 480, de 2006, señaló que el principio de legalidad, en materia sancionadora, no excluye la colaboración de la potestad reglamentaria de ejecución, salvo en aquellos casos en que la propia Constitución ha reservado a la ley y solo a ella disponer en todos sus detalles en una determinada materia (considerando $18^{\circ}$ ).

Esto nos Ilama a reflexionar sobre las matizaciones que afectan al principio de legalidad en el ámbito sancionador municipal.

El sometimiento de la Administración al principio de legalidad se configura como pieza clave del Estado de Derecho, conforme a él los órganos del Estado deben someter su acción a la Carta Fundamental y a las normas dictadas conforme a ella, por lo tanto solo podrán actuar dentro de su competencia y no tendrán más atribuciones que las que expresamente se les hayan conferido, es lo que se ha llamado "vinculación positiva de la Administración al ordenamiento jurídico" (artículos $6^{\circ}$ y $7^{\circ}$ de la CPR y $2^{\circ}$ de la ley $N^{\circ} 18.575$ ). Todo ello, sin embargo, no puede conducir a una reserva de ley total o absoluta, pues significaría una atadura inadecuada para la Administración (esto justifica, por ejemplo, la existencia y el ejercicio de poderes discrecionales).

En cuanto a los municipios, el artículo 118 de la Constitución establece que son corporaciones autónomas ${ }^{37}$, creadas y configuradas, en sus elementos esenciales (organización, funciones, potestades), directamente por el propio texto constitucional, el que es complementado por leyes orgánicas constitucionales ${ }^{38}$. Sin embargo, el legislador puede precisar cuánta autonomía corresponde a un determinado órgano constitucional; pero no puede establecer interferencias externas incompatibles con dicha autonomía ${ }^{39}$.

Desde la perspectiva de la autonomía constitucional de que gozan las municipalidades, es posible formular una relectura del principio de legalidad en la potestad normativa local ${ }^{40}$. En este sentido, el contenido político de la autonomía local y la legitimación democrática directa de los municipios (soberanía popular) explicarían el hecho de que, en este ámbito, la ley pueda operar como

\footnotetext{
${ }^{37}$ Los entes autónomos de carácter constitucional son una innovación de la Carta de 1980, no existían en la Constitución de 1925.

${ }^{38}$ STC rol No $1^{\circ} 80$, de 1989 (considerando $5^{\circ}$ ).

${ }^{39}$ STC roles Nos. 995, de 2007 (considerando 10), y 1669, de 2010 (considerando 18).

${ }^{40}$ Eduardo García de Enterría y Fernández sostenían que "[e]n el caso de la autonomía municipal puede admitirse, desde su garantía constitucional, que los municipios disponen de una competencia residual para desarrollar actividades que consideren de interés para su comunidad, siempre que la Ley no haya ocupado el correspondiente ámbito de actuación reservándolo a otra Administración por entender que exista un interés público prevalente", en García de Enterría y Fernández (2011), p. 476.
} 
marco o límite, dentro del cual se desarrolla con entera libertad la actuación de los órganos locales ${ }^{41}$.

Esta afirmación podría llevarnos a sostener la existencia de una flexibilización de las ordenanzas al principio de legalidad, que permitiría a las municipalidades, dentro del ámbito de sus competencias ${ }^{42}$, regular todas aquellas materias vinculadas con sus funciones nucleares, siempre que en aquellas no se infrinjan o contradigan preceptos legislativos o reglamentarios ${ }^{43}$.

Al efecto, el Tribunal Constitucional ha señalado que los municipios son "órganos que se crean para satisfacer una función administrativa específica, que se realiza con independencia del poder administrador central y que tienen una capacidad más o menos amplia para llevar a cabo dicho cometido" ${ }^{\prime 4}$, agrega que "dicha autonomía es triple, pues abarca la dimensión organizativa, institucional y normativa" ${ }^{\prime 4}$, esta última dimensión es de rango constitucional (sin perjuicio de su configuración legal), subordinada a dicha Carta Fundamental y a su LOC, la cual, en algunos casos, será de ejecución; pero en otros, puede "abordar asuntos locales que son propios de la gestión municipal, y en que no estará pormenorizando o detallando lo señalado en la normativa nacional"46.

${ }^{41}$ Carro Fernández-Valmayor (2004), p. 135.

${ }^{42}$ Artículo 118 de la Constitución y artículos $3^{\circ}$ y $4^{\circ}$ de la LOCM.

${ }^{43}$ En tal sentido la Contraloría General de la República ha señalado que "(...) los municipios no pueden imponer por ordenanzas locales, menores o mayores exigencias que las legales y reglamentarias, tampoco procede que por dicho acto jurídico se establezca un procedimiento que permita a los actuales tenedores de patentes de alcoholes, enmendar los errores o infracciones en que se incurrió al obtenerlas, pues en ese caso se regularía una materia especialmente regida por la ley, siendo improcedente que las sanciones previstas por el ordenamiento jurídico para el caso de infracciones a dicha normativa, sean modificadas o alteradas" (dictamen $\mathrm{N}^{\circ}$ 15.737, de 2000).

${ }^{44}$ STC rol № 216, de 1995 (considerando 8º a propósito de la autonomía constitucional del Banco Central).

${ }^{45}$ STC rol No 1051, de 2008 (considerando 41ㅜ, a propósito de la aplicación a los órganos autónomos constitucionales de la ley de transparencia y acceso a la información pública) y STC rol № 1669, de 2010, considerando $18^{\circ}$.

${ }^{46}$ STC rol No 1669, considerandos 47 y ss. Esa misma sentencia en su considerando 56 indicó: "Que, tratándose de la potestad reglamentaria municipal, sin embargo, es necesario considerar que tiene que existir un espacio para los intereses municipales en la complementación o ejecución de la legislación. En ese sentido, la ley debe regular nacionalmente, pero con una uniformidad básica o esencial. El elemento normativo uniforme o común del legislador nacional debe ser, por lo mismo, no especialmente detallado. Por una parte, porque no puede no considerar las realidades diferentes de cada municipio. Las casi 350 municipalidades que existen en nuestro país, no son iguales. Tienen diferencias geográficas, de clima, de realidad económica, de densidad poblacional. Por la otra, porque el municipio cuenta con órganos representativos de los intereses comunes en su estructura organizativa (el Concejo Municipal, el alcalde). Ellos deben diseñar y aprobar las normas cuyos destinatarios son 
De tal modo, una interpretación estricta del principio de legalidad entra en flagrante contradicción con el reconocimiento constitucional de la autonomía municipal, por ello se debe optar por una interpretación armónica, partiendo de la base de que la legalidad no puede tener la misma fortaleza en todas las materias ${ }^{47}$. Por lo demás, la aplicación rígida del principio dejaría a las municipalidades sin potestad normativa sancionadora ${ }^{48}$.

En suma, como sostiene Alejandro Nieto sin rechazar la exigencia de la reserva legal, puede entenderse que, incluso en los supuestos en que no medie una ley especial previa habilitante, las municipalidades pueden tipificar infracciones dado que cuentan con la cobertura legal que les ofrece de manera genérica su LOCM, en la que se les reconoce una potestad sancionadora genérica en sus tres niveles: normativo, aplicativo y de ejecución; interpretación inspirada en las necesidades sociales de no dejar indefensos a los municipios si sus normas no van acompañadas de la amenaza de sanción en caso de incumplimiento, así como en la de no permitir la impunidad de los infractores ${ }^{49}$.

Por consiguiente, las ordenanzas municipales serían una fuente originaria del Derecho Sancionador.

\section{Problemas y contrapesos de la flexibilización}

Como se habrá podido advertir, el alcalde goza de un amplio poder discrecional para determinar las materias objeto de regulación, esto es, tiene un vasto poder tipificador de conductas $\mathrm{y} / \mathrm{u}$ omisiones infraccionales, por lo que las ordenanzas, junto con la extensión que pueden alcanzar en relación con las temáticas a abordar, presentan un incierto y disparejo alcance en materia sancionatoria que indudablemente produce una desigualdad entre los vecinos, la que estará dada por la mayor o menor iniciativa que tenga la autoridad comunal. Por lo tanto, puede ocurrir que lo que constituya falta en una localidad, en la siguiente no lo sea, o que la misma conducta u omisión esté sancionada con multas de distinta entidad ${ }^{50}$.

los habitantes de la comuna. Llevar la legislación a sus consecuencias prácticas, no puede prescindir de la realidad local".

${ }^{47}$ SANZ (1994), p. 680.

${ }^{48}$ SANZ (1994), p. 687.

${ }^{49}$ Nieto (2012), p. 290.

${ }^{50}$ Caso de la ordenanza de la Municipalidad de Ovalle sobre el "Tendido de corrientes débiles y fuerza" y la de la Municipalidad de Concepción sobre "Instalación de líneas de distribución de energía eléctrica, de telecomunicaciones, de televisión por cable u otros", en donde ambas sancionan la infracción a sus disposiciones con multas sustancialmente diferentes. Así, el primer municipio sanciona el incumplimiento al plazo otorgado para la canalización subterránea de las redes con una 
Además, la relativización de la reserva de ley envuelve el grave riesgo de no señalar cuáles pueden ser esos límites de la reserva, esto es, hasta qué punto es admisible que un municipio regule y tipifique diversas materias.

Ahora bien, la matización propuesta no excluye en ningún caso la vigencia del principio de reserva de ley en el ámbito local, como se verá a continuación.

\section{a. Necesidad de criterios mínimos de antijuridicidad}

La flexibilización propuesta no hace exigible una definición exhaustiva y acabada de cada tipo de ilícito y sanción en la ley, pero no permite la inhibición absoluta del legislador.

En tal sentido, en lo que se refiere a la tipificación de infracciones, corresponde a la ley la fijación de criterios mínimos de antijuridicidad ${ }^{51}$ que permitan a cada municipalidad establecer tipos de contravenciones, esto es, un catálogo de instrucciones mínimas a los autores de las futuras ordenanzas, conforme a las cuales las entidades comunales puedan fijar los distintos tipos de faltas locales y sus medidas represivas, mediante directrices base que los orienten, guíen y condicionen en la valoración que efectúen a la hora de establecer los supuestos de cada infracción.

Tratándose de sanciones, es preciso que la ley establezca las clases de sanciones que se puedan imponer, su relación con los grupos de ilícitos que puedan existir y la determinación de las posibles medidas represivas que cada ordenanza puede disponer en función de la gravedad de los ilícitos que ella misma pueda tipificar.

Estos criterios de base y las clases de sanciones debieran formar parte de la LOCM y estar establecidos de manera general y taxativa en ella o, como lo precisara García de Enterría en España, en una ley especial sobre materia

multa diaria de 0,3 UTM por poste en que se constate la existencia de tendidos aéreos; mientras, la segunda entidad lo hace con una multa de 5 UTM por día de retraso (ello sin perjuicio de lo objetable que constituye el hecho de que las sanciones se hayan formulado utilizando las palabras "diaria" $y$ "por día de retraso" y "por poste").

Sobre este asunto, García de Enterría ha señalado que "Il]as Ordenanzas de un municipio no son ni superiores ni inferiores a las de otro municipio distinto, son simplemente distintas, sin que sea posible entre ellas ninguna comparación", en GarCía de Enterría y Fernández (2011), p. 230.

${ }^{51}$ Esta terminología fue utilizada por primera vez en la sentencia del Tribunal Constitucional español rol № 132/2001, de 8 de junio de 2001, Fundamento Jurídico № 6 (párrafo segundo). Este fallo intentó precisar, de manera definitiva, el alcance de la ley en materia sancionatoria respecto de las ordenanzas municipales. Versión completa disponible en: http://hj.tribunalconstitucional.es/HJ/es-ES/Resolucion/ Show/SENTENCIA/2001/132. [Visitado el 23.10.2015]. 
sancionadora local que permitiera a las entidades locales el ejercicio de la potestad sancionadora por infracción de las correspondientes ordenanzas ${ }^{52}$.

Partiendo de la base de que la potestad normativa sancionadora les permite a las municipalidades mediante la elaboración de ordenanzas regular todas aquellas materias que son inherentes a sus funciones y que tendrán vigencia en el territorio de la comuna, con la finalidad de satisfacer las necesidades de la comunidad local, podemos enumerar una serie de criterios susceptibles de ser empleados para tal efecto, por ejemplo ${ }^{53}$ : a) una perturbación o alteración relevante y significativa de la convivencia local que afecte de manera inmediata y directa a la tranquilidad o al ejercicio de derechos legítimos de otras personas, al normal desarrollo de actividades de toda clase conformes con la normativa aplicable o a la salubridad u ornato públicos; b) el impedimento del uso de un servicio público a otra u otras personas con derecho a su utilización; c) el impedimento u obstrucción al normal funcionamiento de un servicio público; d) actos de deterioro grave y relevante de equipamientos, infraestructuras, instalaciones o elementos de un servicio público o bien nacional de uso público sujeto a su competencia, entre otros.

Los anotados ejemplos deben estar estrechamente vinculados a las relaciones de convivencia comunal y del uso de sus servicios, equipamientos, infraestructuras, instalaciones y espacios públicos. Los criterios podrán ser establecidos en ausencia de normativa sectorial específica.

Por último, cabe recalcar que esta flexibilización no supone, ni remotamente, la aceptación de ordenanzas locales tipificadoras de infracciones y sanciones sin alguna, aunque sea mínima, cobertura legal, como se verá a continuación.

\section{b. Límites a la flexibilización}

En cuanto a los límites, cabe anotar que esta flexibilidad no excluye la presencia de contrapesos materiales y formales al ejercicio de esta potestad, la cual ha sido acotada a ciertos límites por el legislador, como ya se habrá podido advertir.

En efecto, el primer límite material lo constituyen las "funciones", por lo que si bien el alcalde tiene una amplia gama de aspectos a regular, estos se restringen a las materias de su competencia exclusiva señaladas en su ley orgánica, como

\footnotetext{
52 García de Enterría (1993), p. 62.

53 Para realizar esta enumeración se tuvo a la vista la regulación española sobre la materia, contenida en los artículos 139 y siguientes de la Ley Reguladora de las Bases del Régimen Local (LRBRL), modificada por la ley $N^{\circ}$ 57/2003, de 16 de diciembre, de medidas para la modernización del gobierno local, también conocida como "Ley de grandes ciudades".
} 
serían el aseo, el ornato o el uso de bienes nacionales de uso público ${ }^{54}$. El segundo está constituido, naturalmente, por la necesaria observancia del principio de primacía de la ley, lo que significa que las ordenanzas no pueden establecer limitaciones adicionales a las que prescriben las leyes y los reglamentos para la materia específica que se trate, puesto que ello contravendría la normativa constitucional y legal ${ }^{55}$. Tercero, en lo que atañe al establecimiento de sanciones por las ordenanzas, la LOCM exige, únicamente, que estas tengan carácter pecuniario, lo que parece, por tanto, excluir la existencia de otras de distinta naturaleza ${ }^{56}$, salvo que una norma legal disponga otro tipo de sanciones, como ${ }^{54}$ Las municipalidades no pueden dictar ordenanzas que reglamenten el izamiento obligatorio del
pabellón nacional y la sanción por su incumplimiento, porque la reglamentación del uso de la bandera
nacional u otros emblemas patrios es de competencia del Presidente de la República a través del
ejercicio de su potestad reglamentaria, sin perjuicio de la facultad de los gobernadores para otorgar
las autorizaciones específicas u ordenar el izamiento del pabellón nacional acorde a la normativa
vigente. Por otra parte, no existen en el ordenamiento jurídico vigente normas que otorguen a las
municipalidades funciones relacionadas con el uso de emblemas nacionales, por lo que carecen de
competencia para regular su uso y establecer multas a infractores, ya que la ley No 18.695 solo les
permite sancionar con multas tratándose de incumplimientos a las ordenanzas municipales, las que
no pueden reglamentar la materia analizada (dictamen $\mathrm{N}^{\circ} 14.879$, de 1993).
Asimismo, "no se ajusta a derecho decreto municipal que establece la 'Ordenanza de playas y balnearios
de la comuna de Arica', publicado el $31 / 12 / 97$. Ello, porque a las municipalidades corresponde
conforme art/5 letra c) de ley 18695, administrar los bienes municipales y nacionales de uso público,
incluidos su subsuelo existente en la comuna, salvo que atendido su naturaleza y fines y acorde la
ley, ello corresponda a otros órganos de la administración, como es el caso de las playas de mar (...)"
(dictamen $\mathrm{N}^{\circ} 142$, de 2000).

${ }^{55}$ En este sentido, la Contraloría General de la República respecto de la ordenanza № 1, de 2013, de la Municipalidad de Concepción, "Sobre la autorización de funcionamiento y explotación comercial de máquinas electrónicas o mecánicas de habilidad o destreza", ha señalado que "(...) los artículos $7^{\circ}, 10$-numerales 2 y 3-, 11 y 17, de la ordenanza en examen, regulan, respectivamente, el espacio físico que cada máquina debe ocupar y, a consecuencia de ello, el número de aquellas que puede operar en el local; la exigencia de un informe de un prevencionista de riesgos que certifique que el establecimiento cumple con las condiciones de seguridad e higiene requeridas por la normativa vigente; la permanencia de una persona adulta a cargo; la jornada de funcionamiento; y la obligación de mantener un libro de inspección. (...) Sobre los mencionados aspectos, es del caso manifestar que los preceptos aludidos constituyen limitaciones adicionales a las que prescriben las leyes y los reglamentos para ejercer la actividad económica de que se trata, contraviniendo de este modo la mentada normativa constitucional y legal", en dictamen № 7.368, de 2014.

${ }^{56}$ Al efecto, resulta interesante el dictamen No 59.480, de 2011, que señala que "(...) del análisis de la ordenanza en comento se infiere que ella estableció disposiciones generales relativas a la promoción y a las consecuencias que se producen por no acudir a clases-como el procedimiento que se activa cuando existen tres inasistencias injustificadas durante un mes calendario y las sanciones que no están previstas en el artículo 12 de la Ley No 18.695-, que además, contiene preceptos que contravienen la normativa sectorial, al no contemplar excepciones a la exigencia mínima de asistencia, y que su articulado, debido a su generalidad, excede el ámbito de regulación del reglamento interno de funcionamiento de un establecimiento educacional, todo lo cual constituye una vulneración del referido principio de juridicidad". 
ocurre en materia de alcoholes o de urbanismo y construcción. Asimismo, para la determinación de la cuantía habrá que tener en cuenta, además, los límites constituidos por el respeto de los principios del Derecho sancionador y, singularmente, de los principios de proporcionalidad y audiencia del interesado, así como por la necesidad de ponderación de las sanciones a imponer en función de la gravedad del ilícito ${ }^{57}$.

En cuanto a los límites formales, cabe recordar que el primer control lo efectúa el Concejo Municipal, órgano que deberá votar la aprobación de la norma, verificando que esta se ajuste a la ley (materia regulada, tipo de sanción, cuantía de las multas, entre otros). Enseguida, existe el control ciudadano, el control del pueblo, el cual podrá impugnar la legalidad de la ordenanza sea mediante un reclamo de ilegalidad municipal (que puede concluir en una revisión por parte de los tribunales ordinarios de justicia) ante el Tribunal Constitucional o ante la Contraloría General de la República.

Como queda en evidencia, esta especie de flexibilización de las ordenanzas al principio de legalidad se traduce en el hecho de que la ley actuaría como "marco" dentro del cual se moverían, con libertad de actuación, las entidades comunales.

\section{c. Efecto vinculante de los criterios mínimos de antijuridicidad y las clases de sanciones}

Estimo que el establecimiento de criterios mínimos de antijuridicidad y de las respectivas clases de sanciones, sea en la LOCM o en una ley especial complementaria, debiera ser de aplicación obligatoria para el establecimiento de todo tipo de ordenanza que contenga disposiciones represivas, de modo que solo las conductas u omisiones encuadrables en tales criterios podrían ser válidamente tipificadas como infracciones y consecuencialmente sancionadas ${ }^{58}$.

\footnotetext{
${ }^{57}$ Esto fue zanjado en España a través de la sentencia del Tribunal Supremo de 29 de septiembre de 2003, la cual señaló: "Por último es obvio que, tanto en la tipificación de sanciones como en el ejercicio de la potestad sancionadora, han de respetarse los principios que regulan la materia en nuestro ordenamiento, singularmente las de proporcionalidad y audiencia del interesado, y sin duda también ha de ponderarse la sanción a imponer en función de la gravedad del ilícito valorada según las características demográficas, económicas y sociales del municipio". Este fallo introdujo importantes matizaciones (o, incluso, rectificaciones) al criterio que hasta ese entonces sostenía el Tribunal Constitucional de ese país (véase nota 50), las cuales inciden de manera relevante en el fundamento y alcance de la potestad sancionatoria de los municipios.

Versión completa disponible en: http://www.poderjudicial.es/search/doAction?action=contentpdf\&d atabasematch $=$ TS\&reference $=3069171 \&$ links $=\&$ optimize $=20031025 \&$ publicinterface $=$ true $[$ Visitado el 23.10.2015.

${ }^{58} \mathrm{Al}$ respecto véase ReBollo et al. (2010), p. 149.
} 
Por consiguiente, la eventual inobservancia de una municipalidad a estos criterios supondría una infracción al principio de legalidad, lo que podrá ser denunciado recurriendo a las instancias de control precedentemente señaladas.

\section{Conclusiones}

La potestad sancionadora de la administración, a estas alturas, resulta ser una materia aceptada tanto por la jurisprudencia como por la doctrina mayoritaria. Con ello, se dio paso a la discusión relativa al estatuto jurídico aplicable y a los principios que deben regir su aplicación, siendo la doctrina de las "matizaciones" de estos últimos la que más incertidumbre y variopintas interpretaciones ha generado.

En materia sancionatoria municipal, estimo que es factible considerar las ordenanzas como el instrumento adecuado para la tipificación de infracciones, partiendo de la base de una aplicación flexible del principio de legalidad, basada en los siguientes argumentos:

En primer lugar, la flexibilización del principio de legalidad, el cual actuará como marco o límite del ejercicio del ius puniendi municipal, se puede justificar en la autonomía constitucional y en el carácter representativo de las municipalidades, puesto que el alcalde y el Concejo Municipal se encuentran legitimados por la voluntad popular, esto es, son elegidos directamente por el pueblo. Por tanto, dado que las ordenanzas emanan de la potestad normativa de los municipios, serían el símil, en el ámbito comunal, de las leyes dictadas por el Parlamento, por lo que tendrían "fuerza de ley" en dicho ámbito.

En segundo término, esta matización no es absoluta, sino que va de la mano de una serie de contrapesos formales y materiales que junto con otorgar legitimidad al modelo represivo, buscan garantizar los principios de base del ius puniendi.

En tercer orden, y de lege ferenda, estimamos que sería acertado que la LOCM o una ley especial estableciera un catálogo de criterios mínimos de antijuridicidad y las clases de sanciones, esto es, un conjunto de directrices que apoyen y orienten la determinación que realizan los municipios al momento de establecer los supuestos fácticos (acción u omisión) de las faltas locales y sus correlativas sanciones.

En cuarto lugar, los criterios y clases de sanciones debieran ser establecidos con carácter vinculante, esto es, de empleo obligatorio por parte de cada municipalidad que quiera contemplar en sus ordenanzas medidas represivas por infracción a sus disposiciones.

En quinto lugar, existe la necesidad de que las ordenanzas realicen un esfuerzo en orden a establecer una escala de graduación de las infracciones, la 
cual le permitirá al juez ponderar con un mayor grado de certeza la cuantía de la sanción en relación con el tipo de acción u omisión infractora.

Por último, la ley podría ponderar la pertinencia de contemplar otras variantes sancionadoras distintas a la multa, como la no utilización de servicios o instalaciones, el decomiso, la retirada de la licencia o autorización, las cuales podrían resultar más eficaces o más adecuadas a la infracción que las multas ${ }^{59}$.

\section{Bibliografía CITADA}

Aróstica Maldonado, Iván (1987): "Algunos problemas del Derecho Administrativo Penal", en: Revista de Derecho (año LV, № 182), pp. 71-81. Aróstica MaldONADO, Iván (1991): "Un lustro de sanciones administrativas", en: Revista de Derecho Público (№ 50), pp. 173-195.

Aylwin AzóCAR, Patricio y Azócar Brünner, Eduardo (1996): Manual de Derecho Administrativo (Santiago, Universidad Nacional Andrés Bello).

Bacigalupo, Enrique (2004): Derecho Penal, Parte General (Lima, ARA Editores).

Bermúdez Soto, Jorge (2014): Derecho Administrativo General (Santiago, LegalPublishing-Thomson Reuters).

Camacho Cepeda, Gladys (2010): Tratado de Derecho Administrativo, La actividad sustancial de la administración del Estado, PANTOJA BAUZÁ, Rolando [coord. académico] (Santiago, Abeledo Perrot-LegalPublishing), tomo IV.

Cerezo Mir, José (2008): Derecho Penal, Parte General (Buenos Aires, B de la F Editores).

Cordero Quinzacara, Eduardo (2014): Derecho Administrativo Sancionador. Bases y principios en el derecho chileno (Santiago, LegalPublishing-Thomson Reuters).

Cordero Quinzacara, Eduardo y Aldunate Lizana, Eduardo (2012): "Las bases constitucionales de la potestad sancionadora de la Administración", en: Revista de Derecho de la Pontificia Universidad Católica de Valparaíso (No 39), pp. 337-361.

Cordero Vega, Luis (2015): Lecciones de Derecho Administrativo (Santiago, LegalPublishing).

Deluss, Georges (1998): Droit pénal et droit administratif. L'influence des principes du droit pénal sur le droit administratif répressif (Paris, LGDJ).

Forsthoff, Ernest (1958): Tratado de Derecho Administrativo (Madrid, Instituto de Estudios Políticos).

${ }^{59}$ Nieto (2012), p. 90. 
García de Enterría, Eduardo (1976): "El problema jurídico de las sanciones administrativas", en: Revista de Derecho Constitucional (No 10), pp. 399-430.

García de Enterría, Eduardo (1993): "La problemática puesta en aplicación de la LRJ-PAC en el caso del Real Decreto 1398/1993, de 4 de agosto, que aprueba el Reglamento de procedimiento para el ejercicio de la potestad sancionadora: Nulidad radical del Reglamento y desintegración general del nuevo sistema legal", en: Revista Española de Derecho Administrativo ( No 80), pp. 655-678.

García de Enterría, Eduardo y Fernández, Tomás-Ramón (2011): Curso de Derecho Administrativo (Madrid, Civitas - Thomson Reuters), tomo I.

García de Enterría, Eduardo y Fernández, Tomás-Ramón (2011): Curso de Derecho Administrativo (Madrid, Civitas - Thomson Reuters), tomo II.

Garrido Montt, Mario (1997): Derecho Penal. Parte General (Santiago, Editorial Jurídica de Chile), tomo I.

Garrido Montt, Mario (2003): Derecho Penal, Parte General. Nociones Fundamentales de la Teoría del Delito (Santiago, Editorial Jurídica de Chile), tomo II.

Lozano Cutanda, Blanca (1997): "La tensión entre eficacia y garantías en la represión administrativa: aplicación de los principios constitucionales del orden penal al derecho administrativo sancionador con especial referencia al principio de legalidad", en: Pıcó LoRenzo, Celsa [dir.], Las fronteras del Código Penal de 1995 y el Derecho Administrativo sancionador, XI, (Madrid), pp. 41-77.

Moderne, Franck (1993): Sanctions administratives et justice constitutionnelle (París, Economica).

Nieto, Alejandro (2012): Derecho Administrativo Sancionador (Madrid, Tecnos).

Novoa Monreal, Eduardo (1985): Curso de Derecho Penal chileno, Parte General (Santiago, Editorial Jurídica de Chile), tomo I.

Ortuño Rodríguez, Alicia (2009): "La potestad sancionadora de las entidades locales. Especial referencia a las ordenanzas cívicas", en: Fundación Democracia y Gobierno Local, pp. 23-52.

Rebollo Puig, Manuel; Izquierdo Carrasco, Manuel; Alarcón Sotomayor, lucía y Bueno Armijo, Antonio (2010): Derecho Administrativo Sancionador (Valladolid, Lex Nova).

RomÁn Cordero, Cristian (2010): "El castigo en el Derecho Administrativo", en: Derecho y Humanidades (No 16, Vol. 1), pp. 155-171. 
Sanz Rubiales, Íñigo (1994): "Principio de legalidad y potestad sancionadora en la Administración Local", en: Revista de Estudios de la Administración Local y Autonómica (REALA, No 264), pp. 671-690.

Vergara Blanco, Alejandro (2004): Esquema de los principios del derecho administrativo sancionador, en: Revista de Derecho (Universidad Católica del Norte, Año 11, Nº 2), pp. 137-147.

Yáñez Pérez, Sergio (1985): "Las leyes penales en blanco", en: Gaceta Jurídica (58), pp. 2-15. 